\title{
IMPACT OF EARLY CHILDHOOD CARE AND DEVELOPMENT PROGRAMME IN LEARNING MATHEMATICS
}

\author{
Mukunda Prakash Kshetree*
}

\begin{abstract}
The main focus of the study was to determine overall expected outcomes and learning achievements including assess the effectiveness of Early Childhood Care and Development (ECCD) models conducted in the support of Save the Children (SC) Nepal. The expected outcomes were related to children's school preparedness, learning progresses, promotion, repetition and dropout status. The study was further focused on comparing achievement scores of the students (with and without ECCD exposure) in mathematics and other major subjects. The study also explored important areas for their corrective measures. The study adopted mixed methods research design which employed both quantitative and qualitative primary and secondary data. For the collection of required data, it administered different research tools including classroom observation, school survey forms and semi-structured interview schedules for teachers, parents, management committee members, community based organization (CBO) members and SC local staffs of three districts. The research tools were piloted in four schools located in Kavre district. The sample districts were selected purposively to involve each eco-zone of Nepal such as Siraha, Baglung and Achham from plain, hilly and mountainous region respectively. The study showed that the SC supported ECCD Centers were found above than average standard subjected to set out criteria. Similarly, the learning outcomes and achievements made by the students in major subjects including mathematics with ECCD experience showed significantly higher than those students having no ECCD experience.
\end{abstract}

Key words: Early childhood, care, development, effectiveness, promotion, repetition, dropout, learning achievements

\section{INTRODUCTION AND OBJECTIVE}

This article is based on a study conducted last year in the support of Save the Children (SC) Nepal. In Nepal, Early Childhood Development

* Dr. Kshetree is Associate Professor in Mathematics Education, Department of Mathematics Education, Mahendra Ratna Campus, Tahachal, TU. 
160 IMPACT OF EARLY CHILDHOOD CARE AND DEVELOPMENT ...

(ECD) programme and its activities are still considered as foundation course for basic education. The government of Nepal has been working in collaboration with I/NGOs and CBOs in implementing ECD activities throughout the country by establishing around 34,000 ECD Centers (SC Nepal, 2013). In this regard, SC Nepal has been a major partner for government's ECD programmes since more than three decades long period. It has supported numerous ECD Centers for their establishment and running with quality service delivery throughout Nepal. In this context, it has provided us an opportunity to conduct a research to evaluate the effectiveness of their ECCD programmes and their impact in learning outcomes in major subjects including mathematics. Therefore, this article has focused on learning outcomes and comparing learning achievements, especially in mathematics, of those students who were with and without ECCD experience.

The major objectives of the study were as follows:

- To assess mainly the effectiveness of ECCD programme (conducted by SC Nepal) regarding children's learning outcomes, school preparedness, promotion, repetition and dropout.

- To compare the learning achievements of the students (with and without ECCD exposure) in major subjects especially in mathematics of grade I, III and V.

\section{HYPOTHESIS}

There is significance difference between the learning achievements made by the students with and without ECCD exposure.

Alternative hypothesis $(\mathrm{H}): \mu_{1} \neq \mu_{2}$, where $\mu_{1}$ and $\mu_{2}$ are the mean achievement scores of mathematics of the students with and without ECCD exposure respectively.

\section{REVIEW OF LITERATURE}

In Nepal, the School Sector Reform Plan had aimed at fostering all-round development of children and laying a firm foundation for basic education. Myers's (1990) study on child development claimed, "The early years are critical in the formation of intelligence, personality, and social behavior" (p. 16). The SC, Nepal prepared an ECCD module 2010, which has attempted to ensure children's voices are heard for ensuring their rights to living, development and taking education in child-friendly environment. 
In addition, $\mathrm{SC}$ has emphasized on the effective implementation of existing best practices found in the community regarding child care and development (SC Nepal, 2011). With the focus on these issues and activities, numerous literatures were collected and studied to extract the required ingredients for this study. On the basis of the study of ECCD global program strategy, cooperative programme (UNESCO/UNICEF, n. d.), ECCD Centers Operation Guidelines (2007) and Nepal National Assessment Report, 2013 of major subjects including mathematics, it was outlined the following main principles while developing its research tools including analyzing and interpreting the qualitative information.

- Ensure holistic care and support system for young children: The children should be ensured to get good primary health care, responsive parenting, safety, cleanliness, playing materials, and child-friendly physical and social environment for age-wise learning, growth and development. It also needs to coordinate and integrate child development program with other children's programmes such as health, nutrition, food security etc.

- Make sure the quality early learning environments: Especially for the young children, it fosters play and exploration so that children fully develop their intellectual and social potential. The quality early childhood services provided them (prior to their formal schooling age) safe, caring, play-based, and stimulating learning environment. It helps them to cultivate their literacy, numeracy and mathematics skills along with critical thinking and problem-solving skills. Further, education classes and workshops for parents and teachers are also important to support their care and development.

- Care while transitioning from pre-school to primary school: It happens when the children are of very young age which is a difficult situation to cope with. As a result, it increases a dropout rate. So, the families, pre-schools and schools should provide the enough counseling and support for the children so that they could take their first steps into school confidently and be prepared for academic learning.

- Care on development and learning: The development and learning result from the child's interaction with people and things in his/ her environment (affective and nurturing child-parent relationship reinforces their development and learning). Similarly, the children's learning and development involve their own construction of knowledge 
162 IMPACT OF EARLY CHILDHOOD CARE AND DEVELOPMENT ...

and mathematics learning skills occurred through activity-based experiences.

\section{METHODOLOGY}

It has adopted a mixed method research design as the study blended quantitative and qualitative data both. Effectiveness of ECCD Centers was assessed primarily by observing the Centers and activities undertaken over there. Impact of the Centers and programs on children's later life especially in their regularity in school attendance, achievement in Grades I, III and V and their promotion, repetition and dropout rates were assessed by studying the data/records available in schools. The classroom teaching/learning activities and practices were also observed.

In order to assess the level of ECCD program and compare their impact in learning outcomes of the students in mathematics and other major subjects, the samples of the study also included students without having ECCD experience. While analyzing the data and information, a comparison was made between the children having exposure to SC-supported ECCD program and those without any ECCD exposure. The findings of the study were derived through an empirical field study conducted in ECCD Centers and primary schools of three districts.

This study has used following research techniques:

\section{- School survey form}

It was administered to collect quantitative data related with students' performance in mathematics and other major subjects along with their attendance, promotion, repetition and dropout rates. The form was used for those who were with and without ECCD exposure both. The forms were filled up by using all the documents and records provided by the schools.

\section{- ECCD center and classroom observation form}

It was prepared and used to collect necessary information on overall program inputs, students' adjustment, sociability, group works and participation in learning activities.

\section{- Interview schedules}

It was developed semi-structured interview schedules and used for ECCD facilitators, school teachers, parents, management committee members, SC staff and local implementing partners. Interview schedules 
were used to collect the stakeholders' perceptions on outcomes of ECCD programs especially in the areas of school preparedness and learning outcomes in major subjects including mathematics.

\section{ANALYSIS}

The information and data collected by using various research tools were analyzed by applying qualitative and statistical measures both. The qualitative data collected through observation, semi-structured interviews from ECCD facilitators, school teachers, parents, management committee members, SC staff and members of the local partner organizations were coded, decoded and analyzed critically by categorizing and classifying the responses as received. The data on students' attendance, performance in mathematics and other major subjects, promotion, repetition and dropout rates were analyzed quantitatively by applying some statistical approaches. A comparison of the achievement scores between students with and without ECCD exposure was also treated statistically as follows.

Table 1: Average achievement scores of the students with SC-supported ECCD exposure and without ECCD exposure in Nepali, Maths, Social Studies and English

\begin{tabular}{|c|l|l|l|l|l|}
\hline \multirow{2}{*}{ Grade } & \multicolumn{1}{|c|}{ Type of students } & Mathematics & Nepali & $\begin{array}{c}\text { Social } \\
\text { Studies }\end{array}$ & English \\
\hline \multirow{2}{*}{1} & ECCD experienced & 47.82 & 47.25 & 46.86 & 48.24 \\
\cline { 2 - 6 } & Non-ECCD experienced & 45.21 & 45.34 & 43.64 & 46.40 \\
\hline \multirow{2}{*}{3} & ECCD experienced & 53.44 & 53.70 & 52.83 & 53.27 \\
\cline { 2 - 6 } & Non-ECCD experienced & 47.33 & 48.79 & 49.32 & 45.90 \\
\hline \multirow{2}{*}{5} & ECCD experienced & 48.25 & 52.27 & 52.08 & 50.53 \\
\cline { 2 - 6 } & Non-ECCD experienced & 43.70 & 45.89 & 44.28 & 45.21 \\
\hline
\end{tabular}

Source: Field Survey, 2016.

The table shows that there was a considerably higher achievement of SC supported students having ECCD exposure in each subject in the comparison of those who did not have ECCD experience. 
164 IMPACT OF EARLY CHILDHOOD CARE AND DEVELOPMENT ...

Table 2: Promotion, repetition and dropout rates of the students with and without ECCD exposure

\begin{tabular}{|c|c|c|c|c|c|}
\hline Grade & Type of students & Promotion & Repetition & Dropout & Total \\
\hline \multirow{4}{*}{1} & \multirow{2}{*}{ ECCD experienced } & 231 & 29 & 21 & 281 \\
\hline & & $82.2 \%$ & $10.3 \%$ & $7.5 \%$ & $100.0 \%$ \\
\hline & \multirow{2}{*}{$\begin{array}{l}\text { Non-ECCD } \\
\text { experienced }\end{array}$} & 234 & 33 & 38 & 305 \\
\hline & & $76.7 \%$ & $10.8 \%$ & $12.5 \%$ & $100.0 \%$ \\
\hline \multirow{4}{*}{3} & \multirow{2}{*}{ ECCD experienced } & 222 & 22 & 13 & 257 \\
\hline & & $86.4 \%$ & $5.6 \%$ & $5.1 \%$ & $100.0 \%$ \\
\hline & \multirow{2}{*}{$\begin{array}{l}\text { Non-ECCD } \\
\text { experienced }\end{array}$} & 260 & 18 & 41 & 319 \\
\hline & & $81.5 \%$ & $8.6 \%$ & $12.9 \%$ & $100.0 \%$ \\
\hline \multirow{4}{*}{5} & \multirow{2}{*}{ ECCD experienced } & 227 & 13 & 12 & 252 \\
\hline & & $90.1 \%$ & $5.2 \%$ & $4.8 \%$ & $100.0 \%$ \\
\hline & \multirow{2}{*}{$\begin{array}{l}\text { Non-ECCD } \\
\text { experienced }\end{array}$} & 253 & 33 & 53 & 339 \\
\hline & & $74.6 \%$ & $9.7 \%$ & $15.6 \%$ & $100.0 \%$ \\
\hline
\end{tabular}

Source: Field Survey, 2016.

The processed data clearly shows that the students with ECCD experience were found to have higher promotion rates whereas repetition and dropout rates were lower compared to the students without ECCD exposure in all the three grades.

\section{FINDINGS}

Amongst the different categorical findings, the major ones related with the category of learning outcomes have categorically been put-forth below in some bullets.

- The learning corners (Mathematics, Nepali, English and Social Studies) were found well managed and children were found using the corners most frequently though there were no enough learning materials. However, the learning corners were found messy and mixed up due to small size of the classrooms.

- The teachers trained by SC Nepal were also found using teaching/ learning materials most frequently in most of the classrooms. 
- All the teachers were found paying individual attention and providing immediate support to the children except in a few cases in Siraha and Achham districts.

- The teachers were also found appropriately using the children's mother tongue while conducting playing and learning activities.

- For formal schooling, the ECCD graduates were found better prepared compared to their counterparts without exposure to ECCD, particularly, in emotional, social, physical, language and cognitive aspects.

- The students having ECCD exposure were found higher attendance in average with compared to those who did not have ECCD experience.

- The students with ECCD experience were found to have better personal health habits and involved more in group works compared to the students without ECCD experience.

- The students having ECCD exposure showed significantly higher score than the students having no ECCD exposure in mathematics of all three grades.

- In all three grades, the ECCD exposure students were also found scoring higher in all other major subjects compared to non-ECCD exposures.

- The girls were found having higher achievement scores as compared to the boys in all grades and in all the four subjects. This shows that the ECCD program has higher level of impact on girls compared to those boys.

- The students having ECCD experience were found to have higher promotion rates. But, their repetition and dropout rates were lower compared to the students without ECCD exposure in all the three grades.

\section{CONCLUSION}

In most of ECCD Centers of sample districts supported by SC Nepal, the fundamental requirements have been found to be improved. The major ones were creating child-friendly environment including sitting arrangements, setting subject-wise corners, and use of mother tongue and coordination with parents and management committee. But the situation of improved indicators was found compatible with the human development index and economic condition of the districts. According to which, Baglung is in higher rank followed by Siraha whereas Achham is in the least among them. 
166 IMPACT OF EARLY CHILDHOOD CARE AND DEVELOPMENT ...

The comparative study carried out between two groups of students (with and without ECCD exposure) revealed that their cognitive abilities, learning attitude, social behaviors and emotional maturity are strongly affected by the quality of child-friendly environment, early stimulation and learning opportunities that the children are exposed to ECCD centers. Similarly, it showed that the ECCD programs have significant benefits on school preparedness, health and hygiene, care and support system, reduced school dropout, and increased grade retention. Thus, as an impact of these important factors, the students having ECCD experience have shown higher level of learning achievements in mathematics and other major subjects as well in the comparison of those students' performance who did not have ECCD exposure.

\section{WORKS CITED}

ECCD Centre Operation Guidelines (2007). Early childhood development center operation guidelines (in Nepali). Kathmandu: Department of Education, Government of Nepal.

Myers, R.G. (1990). Programming for early child development and health: The value of combining nutritional and psycho-social intervening and some ways to do it. Kathmandu: unpublished report submitted to Save the Children.

UNESCO/UNICEF (n. d.). Co-operative pogram (Digest No. 30.). Paris: UNESCO.

SC Nepal (Save the Children), (2011). Quality learning opportunities $(Q L O)$ in $E C D$. Kathamndu.

- - - (2013). Healing and education through the arts. Kathmandu. 